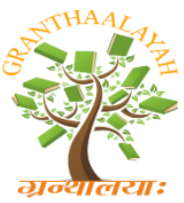
\author{
GRANTHAALAYAH \\ A knowledge Repository
}

INTERNATIONAL JOURNAL OF RESEARCH -

Science

\title{
ROLE OF IMPROVED SEEDS TOWARDS IMPROVING LIVELIHOOD AND FOOD SECURITY AT ETHIOPIA
}

\author{
Girma Abebe *1, Amanuel Alemu ${ }^{2}$ \\ *1, 2 Jimma University, College of Agriculture and Veterinary Medicine, Department of \\ Horticulture and Plant Science, P. O. Box 307, Jimma, Ethiopia
}

DOI: https://doi.org/10.29121/granthaalayah.v5.i2.2017.1746

\begin{abstract}
Seed is a key input for improving crop production and productivity. Increasing the quality of seeds can increase the yield potential of the crop by significant folds and thus, is one of the most economical and efficient inputs to agricultural development. Generation and transfer of improved technologies are critical prerequisites for agricultural development particularly for an agrarian based economy such as of Ethiopian. In Ethiopia, for instance, a unit increase in GDP derived from agriculture has a potential of reducing poverty annually by $1.66 \%$ as compared to $0.73 \%$ poverty reduction expected from non-agricultural sector. Agriculture, particularly crop farming, has a greater effect on both the rural and the urban poor who spend more than a half of their incomes on food. When there are different seed sources available and farmers get access to them there is high probability of adoption of improved varieties.An enhanced seed availability though formal or informal or both sources will improve smallholder farmer's access to seed and enhance improved variety adoption. In practice, whenever a farmer is talking about getting a new seed it implies that she or he is deciding to adopt a new variety. The ultimate goal of a farm household in a risk prone agro-ecology is to obtain seed with characteristics suitable to farmers' agroecological and socio-economic condition. Similarly, seed is pivotal in the improvement of food security and farm household livelihood.
\end{abstract}

Keywords: Improved Seed; Food Security; Seed System.

Cite This Article: Girma Abebe, and Amanuel Alemu. (2017). "ROLE OF IMPROVED SEEDS TOWARDS IMPROVING LIVELIHOOD AND FOOD SECURITY AT ETHIOPIA." International Journal of Research - Granthaalayah, 5(2), 338-356. https://doi.org/10.29121/granthaalayah.v5.i2.2017.1746.

\section{Introduction}

Seed is a fundamental input in crop farming. It has played a critical role in agricultural development since humans domesticated the first crop around 11,000 years ago. It is a carrier of genetic information that controls the maximum crop productivity, resistance to disease, and 
tolerance to environmental stresses such as drought (Cavatassi et al., 2010; Bishaw, 2004). Seed is an essential agricultural input and access to quality seed is of crucial in improving farm household food security in agrarian nations particularly in Sub-Saharan Africa (SSA) and elsewhere.

Agriculture provides food, and jobs for about two-thirds of SSA and contributes about 32\% of Gross Domestic Product (GDP) (The World Bank, 2008). Agriculture led growth in SSA is the most effective and a pro-poor growth strategy than those in the non-agricultural sector (The World Bank, 2005). In Ethiopia, for instance, a unit increase in GDP derived from agriculture has a potential of reducing poverty annually by $1.66 \%$ as compared to $0.73 \%$ poverty reduction expected from non-agricultural sector (Diao et al., 2007). Agriculture, particularly crop farming, has a greater effect on both the rural and the urban poor who spend more than a half of their incomes on food (The World Bank, 2008).

The bulk of human food comes from crops produced from seed. Three dominant cereal crops wheat, rice and maize provide 50\% of human food calories (Fischer and Edmeades, 2010). Seed has unique features as a medium for germplasm exchange among farmers and among farmers and researchers. In short, seed is a medium though which a new crop technology is transferred to farmers. It is the carrier of genetic message for different characteristics embodied in a variety. A seed of particular characteristic represents a variety. Farmers seek particularly seed from offfarm source for numerous reasons. The common reasons are to get a variety of high yielding potential, drought tolerance, disease resistance, a preferred taste, etc. when food crop is considered. When there are different seed sources available and farmers get access to them there is high probability of adoption of improved varieties (Alene et al., 2000). An enhanced seed availability though formal or informal or both sources will improve smallholder farmers access to seed and enhance improved variety adoption. In practice, whenever a farmer is talking about getting a new seed it implies that she or he is deciding to adopt a new variety. The ultimate goal of a farm household in a risk prone agro-ecology is to obtain seed with characteristics suitable to farmers' agro-ecological and socio-economic condition. Similarly, improve seed is pivotal in the improvement of food security and farm household livelihood (McGuire and Sperling, 2011). Therefore, farmers' access to quality seed, as well as the introduction and adoption of improved varieties is of crucial to smallholder farmers in SSA and elsewhere.

Crop productivity is low in (Central Statistical Agency, 2011; Langyintuo et al., 2010). Governments have been pursuing strategies for improving food crop productivity by using improved varieties and application of accompanied agronomic practices, inputs through parastatal agencies seed production and supply (Government of Ethiopia (GoE), 2001). Considerable resources have been devoted to the development and release of improved varieties though their adoption has been remained low (Spielman et al., 2011).For enhanced improved seed supply a well-functioning seed system is deemed crucial (Maredia et al., 1999). In that aspect, a formal seed system that functions adequately feeds informal seed system and they are noted to be complementary (Almekinders et al., 1994). 


\section{Literature Review}

\subsection{Definition and Importance of Seed}

Seed: It is the basic agricultural input, and access to preferred and adapted seed is a prerequisite for sustainable production (Sperling and McGuire, 2010) or, the part of a plant from which a new plant can be grown or a vital input in crop production (Bajrang, 2008). Seed performs various functions in agriculture and as such plays a strategic role in a range of debates, in particular those concerned with rural development and food security, biodiversity, business development, knowledge and technology (Louwaars, 2007). Seed is crucial to food security, hence household nutrition. For example, for rural household to have an adequate diet, they should be able to have a variety of seeds which allow them to produce different types of crops. The availability of seed supported by other input and service are importance for increased crop yield and agricultural production and in most cases guarantee household food security. Good supply systems ensure farmers' or households sustained ability to sufficient quality of the desired types of seed at right time (Kiwanuka and Kintu, 2004). Genetic resources (seed) provide the fundamental mechanics that enable plants to convert soil, water and sunlight into something of critical value to human's food.

Diverse genetic resources allow humans to select and breed plants and animals with desired characteristics, thus increasing agricultural productivity (Ahearn et al., 1998).Ever since seed was considered an important vehicle to extend intensified production techniques in developing countries, and the supply system has received considerable attention. Limitations of these systems have led to the development of the concept of integrated seed supply for the use of quality seed, along with other inputs and appropriate cultural practices/husbandry practices, is recognized as the most cost effective way of increasing crop production and productivity. The availability of seed supported by other input and service are importance for increased crop yield and agricultural production and in most cases guarantee household food security. Good supply systems ensure farmers' or households sustained ability to sufficient quality of the desired types of seed at right time (Kiwanuka and Kintu, 2004).

\subsection{The Concept of Seed Security}

Seed security can be defined as a situation where farmers are certain, year after year, to obtain on time the quality and quantity of seed necessary to fulfill their production plans, and it has two important attributes namely the availability of and access to quality seed. Emphasis is also placed on the timing (that is availability of seed planting), and quality access to availability seed for all farmers in the community (FAO, 1998b).Achieving seed security is quite different from food security, despite their obvious links. One can have enough seed to sow a plot but lack sufficient food to eat, for example during'Hunger season' prior to harvest. Conversely, a household can have adequate food but lack access to appropriate seed for planting, despite these importance differences between food security and seed security, determination of seed security are invariably based, implicitly or explicitly, on food security assessment (McGuire, 2007). To strengthen food and seed security over the longer term, efforts might need to focus on broad strategies for crop diversification. Fortunately, the local government is moving in this direction (Berg, 2002). 
Seed security clearly distinguishes between seed availability and seed access (Remington et al., 2002). Seed security framework was originally derived from a food security framework, which itself is based on entitlement theory. The entitlement theory of Sen Amartya (1981) views famine as a failure of people's ability to access food rather than as a lack of food availability. Similarly, studies of seed insecurity in most disaster situations increasingly indicate that good quality seed is locally available in many emergencies and that the problem is often that some farmers lack access to this seed (Longley and Sperling, 2002).The resilience of crop production after disasters depends on the indigenous knowledge of farmers in selecting and storing their seed to overcome disasters. Farmers' indigenous knowledge, particularly that of women, in identification, selection and seed storage not only contributes to seed security, but also to genetic diversity and the security of landraces (Tsega, 1994).

\subsection{Strengthening the Informal Seed System in Ethiopia}

Improving the local seed system means improving seed security, enhancing seed quality, and the availability of good varieties and reliable seed source structures. A number of avenues exist for improvements to the small scale farming seed supply system. The most important to build on farmers' knowledge and capacities. Farmers have particular knowledge of their seeds and varieties. They are good selectors of varieties for their own use because they can weigh the different requirements. At the same time, they can consider the needs of the household how the variety fits into the total production system and how it adapts to the environment (Tsega, 1994). The complementarities of the formal and informal sector offer multiple opportunities to develop a well-integrated seed sector in which both formal and informal actors play significant role. Farmers' capacities and knowledge regarding local conditions, seed selection and traditional mechanisms of seed exchange are valuable elements in the functioning of thin formal seed sector.

Instead of replacing this sector the formal sector can build on these elements to address more effectively seed demands of small-scale farmers. Introducing improved seed technology to local condition can help in improving seed production by the small-scale farmers. Farmer based organizations can play an important role in this respect through participatory approaches. Provision of training can further reinforce such farmers 'capability and knowledge. In addition, the regulatory framework can be changed to suit and facilitate community based seed provision systems (Neuendorf, 2004). Integrated seed supply system can be achieved by organizing farmer to produce improved seed in their village. There are seed market niches that can be occupied by organized groups of small-scale farmers. These opportunities are usually neglected by the formal system because the market is not large enough to attract large-scale farmers or because they require hand labor (Pichop et al., 2007).

These market niches need to be identified and suitable conditions developed in order that smallscale farmers may explore them. One strategy is to decentralize and diversify seed supply by the promotion of local seed producers and merchants. And farmers who are known in their community for the quality of their seed may be assisted to develop into small-scale seeds men, thus filling the gaps that the larger formal seed units leave in remote areas or in the market for particular seeds. 


\subsection{Food security Definitions and Concepts}

According to the refined definition of the FAO (2002), food security is defined as a situation that exists when all people, at all time, have physical, social and economical access to sufficient, safe and nutritious food that meets dietary needs and food preference for active and health life. Food security addresses people's risk of not having access to food. There risks can be for example, with respect to employment, prices and food production (Von Braun et al., 1992). Food security at an individual level implies that people must either have a sufficient income to purchase food or the capacity to feed themselves directly by growing their own food. There is a direct link between poverty and food security. More specifically, food security is influenced by individual's capacity to work, individual and household access to land and their control over the land and other productive assets include seeds (FAO, 2003a).

Further food security is also influenced by policies concerning the management of environmental in general and agricultural biodiversity specifically and FAO estimates that $80 \%$ of crop production increase will come from this intensification and crop production. The remaining $20 \%$ will be initiated with the expansion of arable land. One of the primary causes of household food insecurity in Ethiopia is the presence of production risks in the form of drought and pests which result in frequent crop failures, and thus reduced agricultural production and incomes (Degefa, 2005; and Devereaux, 2000).

\subsection{Seed and Food Security}

Definitions of seed security and food security are remarkably similar. Both include aspects of availability, access and utilization (Remington et al., 2010). The aim of household seed security is to help improve and strengthen the household food production capacity thus enabling farmers to retain seed of their preferred local varieties (Almekinder and Louwaars, 1999). For poor farmers with no planting material, seed security refers to access to seed to maintain food production (Zewdie et al., 2008). The two are linked, but far from the same (Sperling, 2000). Seed security and food security come one after the other in agricultural rehabilitation programmes. Thus, seed security, both in normal and disaster years, is a prerequisite for increasing food production, improving farmers' income, alleviating poverty and ensuring food security (Zewdie et al., 2008).

Table1: Parameters for Food and Seed security Assessments

\begin{tabular}{lll}
\hline Parameter & Food security & Seed security \\
\hline Availability & $\begin{array}{l}\text { Sufficient quantity of } \\
\text { appropriate foods is within } \\
\text { reasonable proximity to } \\
\text { people. }\end{array}$ & $\begin{array}{l}\text { Sufficient quantity of seed of } \\
\text { desired crops are within } \\
\text { reasonable proximity to } \\
\text { people (spatial availability), } \\
\text { and in time for critical sowing } \\
\text { periods(temporal availability). }\end{array}$ \\
Access & $\begin{array}{l}\text { People have adequate income have adequate income } \\
\text { Pr other resources to purchase } \\
\text { or barter for appropriatefoods. } \\
\text { Food is properly used (food }\end{array}$ & $\begin{array}{l}\text { or barter for appropriateseeds. } \\
\text { Seed is of acceptable quality }\end{array}$ \\
\hline
\end{tabular}


processing, storage, nutrition, child-care, andsanitation practices). health

and of desiredvarieties (seed health, physiological quality and variety integrity

Source: Remington et al., 2010

\subsection{Seed Supply System and Food Security}

Almekinders (2000) study shows that poverty is strongly related with increased use of off farm seed sources. Poor household are often not capable to save seeds for next planting since their crop production is often below the subsistence level. Wealthier farmers in the village are importance source of local seed. Study by Sperling (2003) shows the reasons such as loss of seed due to crop failure, incapability to save seed because of low yield of the previous seasons, need to replace seed because of degenerate or disease contamination, and need to acquire new cultivars may motivate farmers to use off-farm seed; small scale seed production (including strengthening farmers' seed production) small scale seed provision are important for seed availability. In addition, the benefit of small scale farmers from commercial seed activities include, increasing production through increment in productivity, increasing the income of the small farmers and improving agricultural seed and other input market, in addition it is possible to Create changes that will improve the standard of living of the rural population, reducing poverty and improving food security and promoting the transformation toward a sustainable commercial agricultural sector (Giusti, 2004).

Mulatu (2004) finds the informal seed sector very active in the provision of wheat seed, primarily consisting of "recycled" modern varieties that are exchanged under a wide range of arrangements, ranging from gifts to cash sales. The empirical results of Edilegnaw and Detlef (2007) have shown that conservation of varietal diversity on farm is mainly a poor man's undertaking with little access to cash crop farming, markets, improved varieties, and extension. McGuire (2007) study in Western Hararghe Zone used profit regression model to show how maintaining seed security is a central concern for household and drives a numbers of practice in the seed system, and how vulnerability to seed security varies between household and ago ecology.

The result also shows farmers' most important source of planting material is their own saved seed. Study in Eastern Ethiopia about farmers' seed system in case of sorghum by Firew (2008) shows farmers have the capacity to produce good quality seed and seed and grain production which is based on their own seed or seed obtained from farmers seed system. The main storage methods for sorghum seed are first panicles in house, second panicles in the house and thirdly smoking for panicles. For seed security farmers seed system is more important than the formal seed system. Zewdie et al., (2008) reveal that seed security for food security can only be achieved in the developing countries, if strategies and mechanisms are designed to protect the local crop diversity and improve the seed supply sector. However, it should be recognized that the seed supply sector has as its foundation the locally adapted crop varieties, therefore it would not make sense to build a strong seed supply sector without first securing its foundation, which is currently unprotected and under stress. 
The study conducted by Gezahagh (2008) tried to identify major factors that determine the seed multiplication by farmers and its contribution in the Southern Nation Nationality and Peoples Region using To bit econometric model for four major crops (wheat, coffee, apple and potato) in the region. Education, experience, family size, distance from all-weather road and market, extension contact, radio ownership, availability of input credit, ox ownership, size of farm land and training were the hypothesized variables. The report reveals that from hypothesized variables to influence each seed/seedling multiplication that credit and oxen ownership were positive contribution to increase participation and intensity of seed multiplication. Based on result, author recommends efforts aimed at promoting seed/seedling multiplication by farmers should take the importance of additional finance to seed producer farmers for purchase of input including farm oxen. Hence, to sufficiently extend input credit to resource poor farmers, establishment of rural finance institution besides improving the capacity of the existing one contributes very much for such purpose

\subsection{The Role of Improved Seed}

Seed is a key input for improving crop production and productivity. Increasing the quality of seeds can increase the yield potential of the crop by significant folds and thus, is one of the most economical and efficient inputs to agricultural development (FAO, 2006). The Ethiopian agricultural sector has an important opportunity to further develop the seed production sector. Generation and transfer of new technologies are critical prerequisites for agricultural development particularly for an agrarian based economy such as Ethiopia. Seed, especially that of improved varieties, is an essential input for increasing crop productivity. This suggests the need to place much emphasis on sustainable and efficient seed production systems.

Seeds of improved varieties are regarded as effective tools in enhancing crop productivity since it dramatically changed the productivity of crops during the Green Revolution of the1960s to 1980s. Such productivity increase did not happen yet in Ethiopia where the agro-ecology is diverse and farming is a risky enterprise particularly in drought-prone areas (Spielman et al., 2010; Alemu et al., 2008). Adoption of improved varieties of widely grown crops such as tef, maize, sorghum and common beans is low (Spielman et al., 2010). Despite the release of several technologies, particularly of improved crop varieties, there has been limited use of improved seeds by the majority of farmers (CSA, 2010). Among others, unavailability of quality seeds at the right place and time coupled with poor promotion system, is one of the key factors accounting for limited use of improved seeds, which further contributing for low agricultural productivity. Poor availability and promotion of improved seeds is due to inefficiency of the seed systems of the country.

Agriculture is the main stay of Ethiopian economy, having a lion's share in contributing to the national GDP. The current agricultural policy framework of the country, which is known as "Agricultural Development Led Industrialization (ADLI)", sets out agriculture as a primary stimulus to generate increased output, employment and income for the people. Moreover, agriculture is serving as a springboard for the development of other economic sectors of the country (Keeley and Scoones, 2000). 


\subsection{Seed System}

Seed systems are composed of set of dynamic interaction between seed supply and demand, resulting in farm level utilization of seed and thus plant genetic resource. The seed system is essentially the economic and social mechanism by which farmers' demand for seed and various traits they provide met by various possible sources of supply (FAO, 2004). The term seed system represents the entire complex organization, individual and institution associated with the development, multiplication, processing, storage, distribution and marketing of seed in any country. Seed system includes traditional (or informal) system and the nontraditional(or formal or commercial) systems. Legal institutions such as variety release procedures, intellectual property rights, certification programs, seed standards, contract laws, and law enforcement are also an important component of the seed system of any country. They help determine the quantity, quality, and cost of seeds passing through the seed system (Maredia, et al., 1999).

Seed system participants may be relatively few or many, predominantly public or private depending upon the farmers that the system serves. In local systems of seed exchange, farmers often undertake most of the activities that define a seed system. As systems expand to national, regional, and international scales, participants will include the following: farmers, international agricultural research centers, private and public domestic seed enterprises, retailers and distributors, multinational seed companies, private research institutions, farmers associations and cooperatives, banks and credit institutions, trade associations, local governing bodies, donor agencies, national agencies and ministries, community groups (social, religious, etc.), agricultural universities, national agricultural research institutes and NGOs/PVOs. These participants may assume multiple roles in the process of seed provision, performing one or several activities (WBG, 1999).

Seed systems, formal or informal, fulfill a series of functions that are basic prerequisites for expecting the best possible productivity from a crop in a specific situation. Healthy, viable seed of the preferred variety needs to be available at the right time, under reasonable conditions, so that farmers can use their land and labor resources with the best yield expectations. The wrong variety, sown at the wrong time with infected seed of poor germination potential, will seriously limit a farmer's expectation of production and productivity. Thus, any seed system has multiple functions to fulfill - for a range of farmers, farming conditions, and crops in a village, region, or country. A seed system can be assessed at any time according to how well it fulfills these functions. Conditions, situations, groups of farmers, or crops can be identified under which the specific system works well (Welfzien et al., 2001). Activities undertaken to supply seeds to farmers include research and development, multiplication, processing, distribution, and uptake. Other activities that may occur in conjunction with these include transport and storage, as well as quality control (such as seed certification). Seed provision to farmers also includes activities undertaken to influence the process, such as: pricing, financial and technical support, provision of inputs, communication and coordination, as well as market research and promotion. Finally, policy formulation underpins seed systems, defining the boundaries and opportunities for the conduct of all seed system activities (WBG, 1999). 


\subsection{Formal Seed System}

According to FAO (1999), formal seed system as a sector comprises all seed program components, namely; plant breeding, seed production, processing, marketing, extension, quality control and certification that interact among themselves and usually regulated by law. The formal seed sector was set up and organized with the principal goal of diffusing quality seed of improved varieties developed by formal breeding programs. The principal sources of materials for formal breeding programs are the ex situ collections of gene banks. Gene banks contain materials that were originally collected from farmers' systems, that is - in the case of cultivated plants - materials that were developed and maintained by farmers. The formal system has been relatively successful for well-endowed, high-potential areas, but much less successful in more variable, marginal areas. This is partly explained by the fact that improved varieties tend to be poorly adapted to farmers' preferences and production environments. In general, plant breeders have lacked understanding about what farmers in these areas need, developing only few, genetically uniform products for on-farm testing.

Evaluation and selection of new materials was on-station, where conditions are different from those in the target environment (Almekinders, 2000). The formal seed system can be characterized by a clear chain of activities. It usually starts with plant breeding and promotes materials for formal variety release and maintenance. Regulations exist in this system to maintain variety identity and purity as well as to guarantee physical, physiological and sanitary quality. Seed marketing takes place through officially recognized seed outlets, and by way of national agricultural research systems. In formal seed production, seed multiplication occurs through several generations rather than continually recycling the seed of one generation, to avoid building up physical or genetic contamination over time in the same lot of seed (Louwaars et al., 1999).

A major challenge for formal seed supply is to produce sufficient seed of all varieties needed, and deliver it to farmers in a timely manner. This requires considerable organization, time, and space, and incurs risks due to costs and production. To start with, significant area and effort is involved in seed production, though this varies by crop according to its multiplication rate (i.e. how much usable seed is produced per seed sown (McGuire, 2005). The study made by Baniya $e t$ al (2003) signify that, the formal system focuses more on the interests of the seed company, and has more access to biotechnology and plant breeding techniques, so this seed system generally neglects the indigenous knowledge. The market is dominated by a few suppliers with potentially serious implications for technology choice and price fixing.

As of September 2014, a total of 487,472ql of improved seed was distributed by the four seed enterprises and private seed producers. From the total amount, the highest sum went to Oromia, amounting to 171,154ql, Amhara got the second highest amount with 165,590ql, and Southern region got 126,864ql and Tigray got the smallest amount of improved seeds totaling 23,862ql.

From the main cereals improved seed varieties distributed in 2013/14, wheat holds the lion's share with 1.5 million quintals, followed by barley having 284,000ql share, maize comes next with 249,000ql, and tef stands last with 226,000ql. During the last cultivation season, the country 
cultivated 12 million hectares of land with major crops with the expectation of obtaining 300 million quintals of yield, according to (Fasika, T., 2015) of Ethiopia.

Table 2: Area Covered (ha) by Improved Seeds (Formal) during 2006/07 to 2010/11 Cropping

\begin{tabular}{lllcll} 
& \multicolumn{5}{c}{ Season } \\
\hline Crops & $\mathbf{2 0 0 6 / 0 7}$ & $\mathbf{2 0 0 7 / 0 8}$ & $\mathbf{2 0 0 8} / \mathbf{0 9}$ & $\mathbf{2 0 0 9 / 1 0}$ & $\mathbf{2 0 0 1 0 / 1 1}$ \\
\hline Cereals & 429,536 & 335,369 & 412,629 & 430,937 & 322,819 \\
Pulses & 5,224 & 5,025 & 6,309 & 14,918 & 12,912 \\
Oil crops & 1,833 & 4,056 & 2,273 & 2,328 & 9,139 \\
Vegetables & 779 & 559 & 501 & 1,899 & 2,788 \\
Root crops & 813 & 2,114 & 2,251 & 799 & 3,721 \\
Other annuals & 70 & 102 & - & - & -- \\
Permanent & 9,681 & 11,742 & 5,828 & 13,120 & 9,852 \\
\hline Total & $\mathbf{4 4 9 , 1 8 6}$ & $\mathbf{3 5 9 , 9 3 7}$ & $\mathbf{4 3 2 , 1 0 7}$ & $\mathbf{4 6 5 , 8 0 9}$ & $\mathbf{3 6 4 , 1 5 4}$
\end{tabular}

Source $=$ MOARD 2012

\subsection{Subsistence Agriculture}

Ethiopian agriculture is characterized by the use of inadequate production technologies that in a variable climate produces important fluctuations in crop yields, uncertainties, and food insecurities. Access and availability to improved production technologies including seed, fertilizers mechanization and markets are limited. The most recent estimate by the Ethiopian Central Statistical Authority (CSA, 2009) indicates, from a total cultivable area of 12.8 million ha, only about 8 million ha is under cereal crops1. Various studies indicate that improved seeds are used in less than 3\% of the total cultivated area (See Table 1). For smallholder farmers, the main constraints are availability and affordability to quality seeds. This is particularly the case for poor farmers in remote and isolated villages. Given the low level of improved seeds and fertilizers in use, it is clear why agricultural productivity has been lagging behind. This has resulted in chronic food insecurities and pervasive poverty both in rural and urban centers across the country.

\subsection{Informal Seed System}

Informal or on-farm seed system, vary among country, region and crops. They rely on seed saving practices, that is, keeping parts of the harvest for planting in the next season. The system usually plants local varieties of seed kept from the previous year's harvest, obtained from neighbors and/or the local market. This is the predominant system for food crops in subsistence agriculture .It is estimated that in developing countries, the informal seed system is responsible for more than $80 \%$ of the total area planted with subsistence crops .It is very resilient system, which is very active even without the support of public or private institutions. On farm seed system are essential for improving food security for developing countries. They will likely to continue to be the main source of seed for subsistence crops in the world. This system is not market oriented; seeds are usually produced for consumption. Some surplus can be bartered with neighbors or sold to local grain dealers (FAO, 2004). 
As a study made by GTZ (2000) clearly states, for small-scale farmers in developing countries, management of seed is of crucial importance and forms an integral part of their crop production systems. For many centuries, farmers have developed and maintained their own plant genetic resources, based on local means of seed production, selection and exchange. Introgressions, mutations and introductions from elsewhere are the common sources of new genetic material in a community. Newly introduced varieties are subject to farmers' experimentation, and when adopted they become part of the local gene pool. In many cases, this integration involves physical mixing of seeds and spontaneous crossing with other materials. The informal seed sector has strong local character, without necessarily being confined to a small geographical area.

Table 3: Area Covered (ha) By Local (Informal) Seeds Cropping Season

\begin{tabular}{llllll}
\hline Crop & $\mathbf{2 0 0 5} / \mathbf{0 6}$ & $\mathbf{2 0 0 6 / 0 7}$ & $\mathbf{2 0 0 7 / 0 8}$ & $\mathbf{2 0 0 8} / \mathbf{0 9}$ & $\mathbf{2 0 0 9 / 1 0}$ \\
Cereals & $7,636,935$ & $8,127,710$ & $8,309,899$ & $8,333,097$ & $7,660,560$ \\
Pulse & $7,636,935$ & $1,373,914$ & $1,509,394$ & $1,568,457$ & $1,358,379$ \\
Oil crops & 790,471 & 736,791 & 702,518 & 851,626 & 706,361 \\
Vegetables & 116,298 & 94,636 & 118,026 & 159,626 & 122,832 \\
Root crops & 167,189 & 186,804 & 180,624 & 143,761 & 183,254 \\
Other annuals & 77,000 & 97,575 & 83,041 & 68,048 & 56,431 \\
Permanent & 750,353 & 810,364 & $1,023,591$ & 885,427 & 48,927 \\
\hline Total & $\mathbf{1 1 , 2 9 2 , 5 7 2}$ & $\mathbf{1 1 , 7 8 7 , 7 7 5}$ & $\mathbf{1 2 , 3 8 2 , 4 3 4}$ & $\mathbf{1 2 , 4 9 3 , 9 8 9}$ & $\mathbf{1 2 , 9 5 4 , 7 4 9}$
\end{tabular}

Source $=\quad$ MOARD 2011

\subsection{Integrated Seed System}

The line between the formal and informal seed sectors can become somewhat blurred, as seeds of improved varieties can be saved by farmers and eventually considered as "local variety" or "local seed" after some years of usage. In addition, in Ethiopia there have been attempts made by the government and NGOs to promote quality seed production and distribution through market channels for landrace varieties, although until now the volume they represent is quite small (Atilaw, 2010). Thus, the formal and local seed systems are not always as distinct or separated as the two labels may imply something to integrate and synergize both systems. Current Ethiopian seed policy pushes to modernize and strengthen the formal seed system, encouraging the uptake of new seed varieties. Seed policy is also influenced by donors who are interested in strengthening the national seed system through programs providing technical support and investment.

These include the Program for Africa's Seed System (PASS) of the Alliance for a Green revolution in Africa (AGRA) and the Agricultural Growth Program (AGP). At the regional level, Ethiopia has joined neighboring countries in efforts to foster seed policy harmonization and problem-solving through the Association for Strengthening Agricultural Research in Eastern and Central Africa (ASARECA). This association represents the National Agricultural Research Systems, together with the Common Market for Eastern and Southern Africa (COMESA), which promotes regional trade and investment (Alemu, 2012). 


\subsection{Seed Development, Production and Distribution in Ethiopia}

The Ethiopian seed industry is composed of formal and informal sectors as well as public and private organization. The formal sectors include federal and regional agricultural research establishments, universities, the regulatory organ in the MoARD, and private companies. The informal sectors encompass millions of farmers, who continue to practice seed selection and preservation, just as their ancestors did (Abdisa et al., 2001).The formal system is concerned with the development and distribution of seeds of modern or improved varieties, while local cultivars or landrace varieties are handled by the informal system. The line between the formal and informal seed sectors can become somewhat blurred, as seeds of modern varieties can be saved by farmers and eventually become considered a "local variety" after some years. In addition, in Ethiopia there have been attempts made by the government and NGOs to promote quality seed production and distribution through market channels for landrace varieties, although until now the volume they represent is quite small (Lipper et al.,2005).

The bulk of seed supply in Ethiopia is provided through the informal system. According to data obtained from the NSIA in 2003, the total demand for food grain seeds in the country is approximately 1.4 million quintals per year. In 2005 the formal sector provides around 200,000 quintals or between $10-15 \%$ of the total. The remainder is made up by supplies from the informal sector. Formal breeding and seed multiplication activities were conducted on an ad-hoc basis until the1970s. In 1976, the National Seed Council (NSC) was set up to formulate recommendations for seed production in the formal sector and the release of varieties from the national research programs (Byerlee et al., 2007). From their recommendations the Ethiopian Seed Corporation was founded in 1979 as a state enterprise, run through the Ministry of State Farms, Coffee, and Tea Development (Dabi et al., 1998).

Despite the crucial importance of improved seed in bettering the livelihoods of small-scale farmers, in Ethiopia access to this invaluable technology is still constrained by many factors. One important factor is the underdeveloped seed industry. Independent studies have estimated a large annual demand for seed, which is never met or (in the case of hybrid maize and sunflower) is met only through imports (Alemu et al., 1998) project, had two main components: seed enterprise development and capacity building. The former component was intended to improve the supply of quality seed of landrace and modern varieties by providing support to the ESE. In addition, support for the promotion of seed multiplication among farmers through the Farmers Based Seed Production and Marketing Scheme (FBSPMS) came under this component (Lipperet al., 2005).The intention was that this scheme would double the total national production of Certified Seed, while making this seed more available to farmers by virtue of the decentralized approach, as the seed could be sold directly to district MoA offices, or reach neighboring farmers through in formal exchange. With this widely-dispersed approach, the FBSPMS sought to be more effective in meeting local demand, and supply seed in a timely and affordable manner. A further goal of the scheme is to organize the most successful seed-producing farmers into producer groups, and support these groups in becoming small independent enterprises specializing in seed production (McGuire, 2005). 


\subsection{Status of the Ethiopian Seed Industry}

Seed system in Ethiopia represents the entire complex organizational, institutional and individual operations associated with the development, multiplication, processing, storage, distribution, and marketing of seed in the country (Fischer and Edmeades, 2010. Farmers, particularly smallholder ones, are involved in multiple kinds of seed systems, which can guarantee them in obtaining the quantity and quality of seeds they need and to market their produce (Atilaw,2010). Seed systems in Ethiopia can be divided into two broad types: the formal system and the informal system (Atilaw, 2010). Both systems are operating simultaneously in the country and difficult to demarcate between the two. There is however, a fact that the formal system is the original source of improved seeds in the informal system. There is also a system that interact the two systems referred to as integrated seed system. Other forms of seed systems operating in both systems also exist such as Community-Based Seed System (CBSS). Though not well developed, few commercial seed systems are also operating in the country (Atilaw, 2010).

\subsection{Nature of Seed Marketing}

Seed marketing is the most important as well as a challenging aspect of seed industry because of the nature of the product. Seed being a living organism, its quality deteriorate faster. Thus, its shelf life is limited and it must be marketed within the season. Another peculiar feature of seed is that it requires two to three years lead time to meet the specific requirements that is to meet the demand for particular seed, its production has to be organized at least two years in advance. The changes in the weather, price of crop, and price of competing crop, may change the prospects of demand for seed of particular variety at the commencement of sowing season (Singh, 2004). The nature of seed demanded by farmers differs. Large- and medium-scale farmers use markets to purchase uniform genetic materials that are highly responsive to chemical inputs and embody specific characteristics (e.g., color, uniformity of grain size) rewarded by the market. By contrast, more subsistence-oriented smallholders may value characteristics such as drought tolerance, early maturity or good storage more than fertilizer responsiveness. Because of the small size of their land holdings, mixed cropping practices, and strategy of minimizing production risks by diversifying the variety base, smallholders also demand relatively small quantities of seed but for a number of varieties of the same crop and recycle seed over more seasons than larger commercial farmers (Maredia et al., 1999).

Seed demand from different users can be met by promoting a range of seed organizations with comparative cost advantages in supplying seeds of distinct commodities to different groups. For example, multinational seed companies can meet the seed needs of large-scale commercial farmers whose quality requirements and willingness to pay are higher than smallholder farmers. The seed needs of the latter group can be met more effectively by small-scale firms' or Community-based Seed Multiplication and Distribution Schemes such as farmers seed groups and Cooperatives (Maredia et al., 1999). The largest problem faced by seed multiplication program elsewhere in Africa is difficulty of building a sustainable seed market. Small quantities of seed are being profitable sold with in the village community. Sales are strongest for newly introduced varieties. But most small-scale farmers are unwilling to pay premium price to their neighbors for seed they can obtain from their own harvests (Rohrbach et al., 2002). According to Tsigedingle (2003), from the total seed produced by farmers in 1998/99 in the SNNPR only 
$10.7 \%$ was purchased by as a seed WTC, $6.8 \%$ exchanged through informal system as seed to neighbors and relatives, $26.6 \%$ was used for home consumption and $55.9 \%$ sold as grain similarly from 1999/2000 produced wheat seed, 40.6\% was purchased by WTC the rest used as own seed and sold as grain to the market.

\subsection{Source Seed Quality Assurance Mechanisms in Ethiopia}

Seed is one of the most important sources of innovation, particularly in resource-constrained small farm environments. It carries the genetic potential of the crops, determining the upper limit on yield and, therefore, the ultimate productivity of other inputs (Jaffee and Srivastava 1992). The responses of all other inputs depend to a large extent upon the quality of seeds used. The direct contribution of quality seed alone to the total production is estimated at $15-20 \%$ depending upon the crop and it can be further raised up to $45 \%$ with efficient management of the other inputs. In addition, new roles of seeds are rapidly recognized all over the world for the delivery systems of many innovative biotechnological products, and as carriers of plant protection chemicals, and biological and growth regulators. In order to better understand what a seed system is, we need to look into its three components-technological, economic, and legal. The technological component has to do with variety selection; the economic one involves production and marketing; and the legal component has to do with the rules and regulations governing the previous two aspects. Over the centuries, selectors of improved varieties and seed growers have become increasingly specialized (MoARD, 2010). The availability of quality seeds of a wide range of crop varieties is the key to attain food security. Some of the direct benefits of quality seeds to farmers include enhanced productivity, higher harvest index, reduced risks from pests and other biotic factors and higher profits. Therefore, improving access to good quality seed of improved and adapted cultivars is a critical requirement for sustainable agricultural growth and food security. This paper presents a review of mechanisms of quality assurance for source seeds, i.e., breeder, pre-basic, and basic seeds (FAO, 2010).

\subsection{Successful Seed Production and Marketing Mechanisms}

Greater percentage of improvement in agricultural production has come from the use of improved seed. In essence, no agricultural practices, i.e. fertilization, irrigation etc can improve crop production beyond the limit set by seed. In ensuring this, seeds of new varieties must be made available to the farmers in adequate quantity and quality and at affordable prices, and on time. The development and performance of the seed sector is constrained by many factors which include weak technical capacity, poor market mechanisms, and inefficient enforcement of seed law, information asymmetry, insufficient capital investment and low utilization of innovations.

The most important prerequisite for good crop production is the availability of good quality seeds of high-yielding varieties (Oyekale et al., 2014). The quality of seeds alone is known to account for an increase in productivity of at least 10-15\%.Until farmers are provided with quality seed, particularly the improved varieties, it would be uneconomical for many countries of the world to spend precious foreign exchange on fertilizer or other agric. inputs. Investments in plant breeding varietal development would also be a waste if the improved seed are not passed on to farmers in form of quality seeds. It is important that improved and high quality seeds are 
disseminated to farmers at the right time and in the right quantity and quality; because farming activities depend on a continuous supply of good quality seeds and planting materials.

\subsection{Agriculture in the Ethiopian Economy and Related Policies}

Ethiopia is the second most populous African nation (population estimated to be 84 million copying 1.12 million square km (Central Statistical Agency, 2011). The county's economy relies heavily on agriculture. The sector contributes about $41 \%$ of the GDP and employs $83 \%$ of the economically active population (National Bank of Ethiopia, 2011). The major cereal crops cultivated in the country are tef $(2,761,190 \mathrm{ha})$, maize $(1,963,179 \mathrm{ha})$, sorghum $(1,897,733 \mathrm{ha})$, wheat $(1,553,240 \mathrm{ha})$, and barley (1,046,555 ha). Pulses are important grain crops for cash earning as well as for food production (Central Statistical Agency, 2011). Although farming is the foundation of the country's economy, crop productivity has remained low. For instance, the average national yield of important food crops such as tef, maize, sorghum and wheat were 1.26, 2.54, 2.08 and 1.84 tons per hectare respectively (Central Statistical Agency, 2011) while the potential of those crops is two to three times higher (MoARD, 2008).

Low crop productivity in SSA including Ethiopia is due to a limited use of seeds improved varieties by smallholder farmers. The supply of certified seeds of grain crops in Ethiopia is estimated to be about $10 \%$ of the annual seed planted (Spielman et al., 2010). Seed is a divisible and scale-neutral technology that can be adopted by different categories of farmers - from resource poor to resource rich. Farmers' access to seeds of adapted varieties of modern or landrace to their agro-ecologies is critical in increasing food production (Feder et al., 1985). However, deficiencies have been observed in improved seed supply due to inadequacies in seed varieties demanded and quantity required, prices, and untimely seed delivery (Sahlu et al., 2008). The capacity of seed supply and seed dissemination is highly influenced by a country's seed system development stage (Maredia et al., 1999). The transition from one stage to another stage, however, is not linear but dictated by economic, agricultural development and seed system development stage of a particular country and crop. For instance, some crops attract commercial enterprise while others do not; hence, seed system development requires policy intervention (Tripp and Louwaars, 1998).a has put great emphasis on increasing the production and productivity of small-scale farmers. Seed is a key input for improving crop production and productivity. Increasing the quality of seeds can increase the yield potential of the crop by significant folds and thus, is one of the most economical and efficient inputs to agricultural development (FAO, 2006). Generation and transfer of new technologies are critical prerequisites for agricultural development particularly for an agrarian based economy such as Ethiopia. Seed, especially that of improved varieties, is an essential input for increasing crop productivity.

In Ethiopia, different seed production systems exist parallel to one another: informal seed systems, community-based seed systems, formal seed systems (government supported) and commercial seed systems. The informal seed systems (self-saved seed or farmer-to-farmer seed exchange) accounts for $80-90 \%$ of the seed used by smallholder farmers (Zewdie, et al, 2008).In the formal system, the role of Ministry of Agriculture and Rural Development (MoARD),Ethiopian Institute of Agricultural Research (EIAR), Ethiopian Seed Enterprise (ESE) and Regional Seed Enterprises (Oromiya Seed Enterprise, Amhara Seed Enterprise and Southern Region Seed Enterprise) are crucial in breeding, releasing varieties, production of breeder, pre- 
basic and basic seeds. In the multiplication of certified seed, the private sector (cooperatives/union, NGOs, etc.) can increasingly play a great role. The emergence of the seed regulations was a response to evolution of technical and economic changes in the seed industry usually prompted by the desire of the society for government intervention (Tripp, 1997b).

\subsection{Performance of Ethiopian Agriculture}

In Ethiopia, $83 \%$ of the estimated 84 million people live in rural areas are depending on agriculture for their livelihoods. The sector contributes $41 \%$ of the GDP of the country. The average cereal yields are low at 1,244kg/ha (World Bank, 2006). Despite the importance of agriculture in its economy, Ethiopia has been a food deficit country since the early 1970s. A close look at the performance of the Ethiopian agriculture reveals that over the last three decades it has been unable to produce sufficient quantity to feed the country's rapidly growing human population(Marja H. et al., 2010).. Even worse, the country has experienced recurrent droughts that claimed the lives of several thousands of people. It is not worthy that food aid has been accounting for a significant proportion of the total food supply in the country. For instance, Ethiopia received 726,640 metric tons of food aid yearly over the 1985-2000 periods (FDRE, 2010). This is equal to about $10 \%$ of the national food grain production.

Therefore, the current main goal of the Government of Ethiopia's ADLI strategy was to raise crop yields through a centralized and aggressive extension-based push focusing on technological packages that combined credit, fertilizers, improved seeds and better management practices. Policy makers assumed that significant productivity growth could be easily achieved by improving farmers' access to technologies which would narrow the gap between farmers' yield and what agronomists called 'exploitable yield potential'. Researchers also reported the existence of technologies that can make a huge difference and shift upwards farmers' yield frontier in grain production. Based on six years average data, researchers indicated that maize yield, for instance, can be increased from current farmers' yield level of 1.6 ton/ha to 4.7 ton/ha, and wheat from 1.1 ton/ha to $2.8 \mathrm{ton} / \mathrm{ha}$ and tef from 0.7 ton/ha to $1.5 \mathrm{ton} / \mathrm{ha}$, if peasants use the right type and amount of improved seed varieties, fertilizers and other recommended practices (Berhane et al., 2004).

In the recent years, agricultural GDP grew at levels close to double figure, a pattern that appears to be confirmed by looking at cereal production growth. Based on the data from Central Statistics Authority (CSA), cereal production in the period 2005/06 to 2009/10 was increased by more than $4 \%$ per year. The yields and area cultivated increased at a rate of $2.5 \%$ and $2 \%$ per year, respectively. The largest increases in all dimensions were in tef, wheat and sorghum.

In the same way, the demand and use of inputs by smallholder farmers have been increased tremendously.

\section{Summary and Conclusion}

Access to 'good seeds' is certainly vital for farmers' livelihood. Characters of good seeds are universal in many aspects and should be realized for better production. However, good varieties mean different things for different stakeholders/farmers, and they are very much location, timing 
and market specific. Therefore, promotion of good (improved) varieties is a different issue from promoting and securing good quality seeds. Integration between the two is necessary, but they need to be clearly understood as separate matter.

Especially, in order to increase the production and productivity of agricultural output, the use of modern agricultural technologies are vital, out of which fertilizer and high yielding variety of crops are the most important technologies to increase the level of crop production. Clearly, Ethiopia has the potential to increase food production by increasing the area of land under agriculture, though the present availability of quality seeds falls well below present demand.. However, very few are involved in marketing and distributing directly to end-users. Because of the costs associated with certification, the current system excludes small-scale farmers wishing to produce seed. There is a key role to be played by the private sector to bridge the gap between the supply and demand of seed, and make quality seed available to farmers in their villages in the right amount and at the right time. It is expected that the increased supply will also reduce prices, making the technology available to the poorer farmers, and thus increase productivity and economic activity, and reduce poverty and food insecurities across Ethiopia.

\section{Future Prospects}

Effective seed demand assessment mechanisms and genuine involvement of farmers/users during planning phase is crucially important as seed is an expensive product, every seeds produced must be channeled into the seed system. Thus, appropriate systems which can strictly control seed outlets should be in place and demand-driven seed multiplication strategy and supply with value addition in the seed chain (with respect to quality, time and place of supply and fair pricing) should be looked into; two-to-three times seed production per year is needed to fill the huge gap between seed demand and supply. Thus, development of irrigation capacity particularly in the NARS seed system should be given the utmost priority. provide opportunities for consolidation of investments on capacity building, basic facilities, infrastructure and training activities on variety maintenance and initial (breeder) seed production at national and regional levels; establish clear and simple institutional and functional linkages between research and seed producing institutions; formulation and implementation of clear seed policies in the country and establishment of executing institutions is highly important; capacitate experts and extension agents that can strengthen the entire integrated seed system; and as the involvement of the private seed sector is largely motivated by profit making, seed policies and ethics of seed production and marketing should be maintained so that seed quality shouldn't be compromised.

\section{Acknowledgements}

I would like to tanks my coordinator D.r Aduegna mintesenot for their good comment and supplying the reference materials and also grateful tanks to Jimma university college of Agricultural and veterinary Medicine Liberians because of reference material helping and guide me how I can write this paper

\section{References}


[1] Alemu, D., Mwangi, W., Nigussie, M. and Spielman, D. (2008). The Maize Seed System in Ethiopia: Challenges and Opportunities in Drought Prone Areas. African Journal of Agricultural Research 3(4): 305-314.

[2] Alene, A., Poonyth, D. and Hassan, R. (2012. Determinants of Adoption and Intensity of Use of Improved Maize Varieties in the Central Highlands of Ethiopia: A Tobit Analysis $\quad$ Agrekon 39(4): 633-643.

[3] Almekinders, C. (2000). The Importance of Informal Seed Sector and Its Relation with the Legislative Framework. Paper presented at GTZ-Eschborn, July 4-5, 2000.

[4] Almekinders, C. and Louwaars, N. (1999). Farmers' Seed Production: New Approaches and Practices. London: Intermediate Technology Publications.

[5] Almekinders, C. and Louwaars, N. (2008). Supporting informal seed supply. In: M. H. Thijssen, B. Z., B. A. and W. S. Boef (eds). Farmers, seeds and varieties Supporting informal seed supply in Ethiopia. Wageningen Wageningen International, Programme for Capacity Development and Institutional Change, Wageningen University and Research Centre. pp. 87-96.

[6] Almekinders, C., Thiele and Danial, L. (2007). Can cultivars from participatory plant breeding improve seed provision to small-scale farmers? Euphytica 2007(153): 363-372.

[7] Bajrang, L., 2008. Technology Transfer and the Seed Innovation System in India Presented in Bangladesh". Discussion Paper No 7, Friedman School of Nutrition Science and Policy, Tufts University

[8] Beshir, B. and Nishikawa, Y. (2012). An Assessment of Farm Household Diverse Commonbean Seed Sources and the Seed Quality in Central Ethiopia Tropical Agriculture and Development 56(3): 104-112.

[9] Beyene, H. (2008). Adoption of improved tef and wheat production technologies in crop livestock mixed systems in northern and western Shewa zones of Ethiopia. In Agricultural Economics, Extension and Rural Development, Vol. PhD Pretoria.

[10] Bishaw, Z. (2004). Wheat and Barley Seed Systems in Ethiopia and Syria. PhD thesis Wageningen University.

[11] Cavatassi, R., Lipper, L. and Narloch, U. (2010). Modern variety adoption and risk management in drought prone areas: Insights from the sorghum farmers of eastern Ethiopia. Agricultural Economics 42: 279-292.

[12] Central Statisical Authority (CSA) (2010). Agricultural Sample Survey 2009/2010 (2002 Ethiopian Calender). Report on Area and Production of Crops (Private Peasant Holdings Main Season). Vol. IV, Addis Ababa.

[13] Central Statistical Agency (2011). Federal Democratic Republic of Ethiopia Agricultural Sample Survey 2010 / 2011 (2003 E.C.) (September- December 2010) Report On Area and Production of Major Crops (Private Peasant Holdings, Meher Season), April 2011, Vol. I, Addis Ababa.

[14] Edilegnaw Wale and Detlef Virchow, 2007. Production of sorghum varietal diversity on farmers' fields in eastern Ethiopia: Economic explanations and implications for on farm conservation Journal of Agricultural Economics 6(2):41-69.

[15] Fasika,T.,(2015).Report on improved seed Irony Published on2015(Vol)15,No770

[16] Feder, G. (1980). Farm Size, Risk Aversion and the Adoption of New Technology under Uncertainty. Oxford Economic Papers 32(2): 263-283.

[17] Firew Mekbib, 2008. Farmers' Seed System of Sorghum (Sorghum bicolor (L.) Moench) in the Center of Diversity: Seed Quality, Storage, Protection and Security Journal of New Seeds,9(3): 191211

[18] Government of Ethiopia (GoE) (2001). The Government of the Federal Democratic Republic of Ethiopia Rural Development Policies, Strategies and Instruments. Draft Translation. Addis Ababa: Ministry of Information Press and Audiovisual Department. $151 \mathrm{p}$.

[19] Giusti, V, 2004. On Farm Seed Production, a Practical and Participatory Proposal for Seed Production, FAO, Rome, Italy 
[20] Jaffee, S. and Srivastava, J. (1992). Seed System Development. The Appropriate Roles of the Private and Public Sectors. The World Bank Discussion papers The World Bank, Washington, D.C.

[21] Kiwanuka .S. and J. Kintu, 2004. Seed security in Uganda: Current Status, Issues and Challenges. Journal of agricultural science, 9:17-22.

[22] Langyintuo, A. S., Mwangi, W., Diallo, A., MacRobert, J., Dixon, J. and Bänziger, M. (2010). Challenges of the maize seed industry in eastern and southern Africa: A compelling case for private-public intervention to promote growth. Food Policy 35: 323-331.

[23] Longley, C. and L. Sperling, 2002. 'Do Farmers Need Relief Seed? A Methodology for Assessing Seed Systems'. Disasters. 26:4 pp. 343-355.

[24] Louwaars N., 2007. Seeds of Confusion: the Impact of Policies on Seed Systems. A PhD Dissertation Presented to Wageningen University, The Netherlands 151p.

[25] Mekbib, F. (1997). Farmer Particiaption in Common bean Genotype Evaluation: The case of Eastern Ethiopia. Expl Agric. 33: 399-409

[26] MoARD (2008). Crop Variety Register. Animal and Plan Health Regulatory Directorate Crop Development Department. Addis Ababa: Ministry of Agriculture and Rural Developmen (MoARD). $190 \mathrm{p}$.

[27] MoFED (2010). The Federal Democratic Republic of Ethiopia Growth and Transformation Plan (GTP) 2010/11-2014/15 Draft. Ministry of Finance and Economic Development (MoFED), September 2010. Addis Ababa

[28] National Bank of Ethiopia (2011). Annual report VII. Addis Ababa.

[29] Maredia, M., Howard, J., Boughton, D., Naseem, A. and Wanzala, M. (1999). Increasing Seed System Efficiency in Africa: Concepts, Strategies and issues. MSU International Development Working Papers 77, Michigan.

[30] Pichop, R.C., V.A Tonapi, P.G Bezkorowajnyj, S.S Navi, and N. Seetharama, 2007. Seed System Innovations in the Semi-Arid Tropics of Andhra Pradesh, International Livestock Research Institute (ILRI), ICRISAT, Patancheru, Andhra Pradesh, 502 324, India.

[31] Remington, T., J.Marok, S,Walsh,P. Omanga, and E.Charles,2002. 'Getting Off the Seedsand-tools Treadmill with CRS Seed Vouchers and Fairs'. Disasters. 26:4 pp. 316-328

[32] Sahlu, Y., Simane, B. and Bishaw, Z. (2008). The farmer-based seed production and marketing scheme: lessons learnt. In: M. H. hijssen, Z. Bishaw, A. Beshir and W.S. de Boef (eds). Farmers, seeds and varieties: supporting informal seed supply in Ethiopia, 33-47 Wageningen: Wageningen International

[33] Spielman, D., Byerlee, D., Alemu, D. and Kelemework, D. (2010). Policies to promote cereal intensification in Ethiopia the search for appropriate public and private roles. Food Policy 35: 185194.

[34] Spielman, D., Kelemwork, D. and Alemu, D. (2011). Seed, Fertilizer, and Agricultural Extension in Ethiopia. Ethiopia Strategy Support Program II (ESSP II) Working Paper 020. Addis Ababa.

[35] Tsega, M., 1994. An Inventory and Investigation of the Optimum Local Seed Storage Methods in Wello and Shewa Administrative Regions. SOS/Ethiopia, Addis Ababa, Ethiopia

[36] Teshome, A.,L. Fahrig, J.K. Torrance, J.D. Lamber, J.T. Arnason, B.R., Baum, 1999. Maintenance of sorghum bicolor, Poaceae land race diversity by farmers' in Ethipia Economic botany 53:79-89.

[37] Von Braun,J., Bouis, H.,Kumar,S., and R.Lorch ,1992.Improving Food security of the poor: Concept, Policy and Programs.IFPRI,Washington,D.C. IFPRI.

[38] Zewdie Bishaw., and A.R.T. Gastel, 2008. ICARDA's Approach to Seed Delivery in Less Favorable Areas Through Village-Based Seed Enterprises: Conceptual and OrganizationalIssues. Journal of New Seed.9:1 pp 68-88.

\footnotetext{
*Corresponding author.

E-mail address: girmaabebe1212@gmail.com
} 